\title{
Transitioning Responsibly Toward a Circular Bioeconomy: Using Stakeholder Workshops to Reveal Market Dependencies
}

\author{
Anne-Charlotte Hoes ${ }^{1}$ (D) $\cdot$ Simone van der Burg ${ }^{1} \cdot$ Greet Overbeek $^{1}$
}

Accepted: 18 June 2021 / Published online: 5 July 2021

(c) The Author(s) 2021

\begin{abstract}
This article reflects on the contribution that stakeholder involvement could give to circular bioeconomy transformation (CBE). By comparing argument for stakeholder involvement in literature as well as on our own experiences in six stakeholder involvement workshops, we argue that it is probably unrealistic to fully achieve both normative and co-design goals in a single workshop. Furthermore, stakeholder involvement can help to acquire insight into dependencies in the market and offer an opportunity to connect people to deal with them. Therefore we propose for future stakeholder involvement initiatives for CBE to focus on (1) identify relationships of dependency which make it hard for players in the market to change, (2) develop strategies to change while mitigating the detrimental effects on already existing relationships and (3) gradually breaking down relationships and building new ones that support CBE.
\end{abstract}

Keywords Bioeconomy · Circular economy · Stakeholder involvement ·

Transformation $\cdot$ Market $\cdot$ Dependencies

Stakeholder involvement for the transformation of the current economy to a circular bioeconomy (CBE) is commonly said to serve goals such as inclusive democracy and co-creation. In this article we use our own experiences in six stakeholder involvement workshops, to bring forward a new purpose: to acquire insight into shifting dependencies in the market during sustainability transitions and engage participants in a reflection about appropriate ways to deal with possible negative effects of these shifts. Therefore we propose for future stakeholder involvement initiatives for a $\mathrm{CBE}$ to focus on (1) identification of current relationships of dependency which

Anne-Charlotte Hoes

anne-charlotte.hoes@wur.nl

1 Wageningen Economic Research, Wageningen University \& Research, Wageningen,

The Netherlands 
make it hard for players in the market to transition towards a CBE, (2) development of transitioning strategies that deal with these dependencies carefully. Such transitioning strategies may include (a) allowing to transition gradually, breaking down current relationships and building up new ones and (b) identifying risks and harms related to the transition and attending to them.

\section{Introduction}

Europe is facing a range of environmental, climate, biodiversity and health challenges related to the production and consumption of food and non-food products. Our current economic system depends on fossil fuels, phosphate and synthetic nitrogen fertilizers. These resources are mined or chemically produced and emitted in the environment causing climate change, eutrophication and soil deterioration threatening the availability of clean water, air and soil, as well as the biodiversity and the preservation of a mild climate for future generations (Raworth, 2012). In addition, some products, such as plastics, cause environmental risks as some parts end up as microplastic in the soils and waters of the earth (Yurtsever, 2019).

These challenges are often referred to as 'sustainability challenges'. There are many ways proposed to attend to them. Some focus on scientific breakthroughs that lead to products and production processes which are not polluting, others focus on altering polluting practices or the institutional contexts that support them by means of the development of stricter regulation and again others seek ways to educate and change individual (polluting) behaviour of citizens. The European Commission (2012) aims to attend to all of these aspects (products and processes, practices and institutions or behaviour) at once, when it promotes the transformation towards a circular bioeconomy (CBE) (Blok, 2020; European Commission, 2018; Stegmann et al., 2020). The term circular bioeconomy has several components. The bioeconomy refers to economic activities fuelled by natural renewable resources such as wood, starch and fibres (i.e. biobased products) and renewable energy sources such as sun, wind and water and in which are used to make product. Biobased products refers to the products which are made with such natural materials, such as agricultural or forestry materials. A Bio-based economy is not dependent on depleting fossil resources such as fossil fuels, stones, metals and other minerals. In addition, Biobased products can store $\mathrm{CO}_{2}$, as long as the materials are not composted or burned. The circular economy takes into account the entire life cycle of products. An economy with a circular product design, cascading and sustainable waste management that respects the $3 \mathrm{R}$ principles-Reduce, Reuse, and Recycle it is easier to stay within the carrying capacity of our planet (Inigo \& Blok, 2019).

While the goals of a CBE inspire funding of targeted R\&D programmes, the transformation towards a European CBE is proceeding slowly (Overbeek \& Hoes, 2018). Data from some main market sectors illustrate this statement. For example, in the building sector, building materials such as natural insulation represent only four percent of the total market (Dammer et al., 2015). In addition, bioplastics currently represent about one percent of the 360 million tons of plastic produced annually (http://bio-based.eu/markets; Van den Oever et al., 2017). Moreover, 
global production of fossil-based plastics continues to grow: 311 megatons were produced in 2014 compared to 15 megatons in 1964 (World Economic Forum, 2016).

An important challenge for the realisation of a CBE is perceived to be "the current small size of bio-based markets" (Stegmann et al., 2020, p. 1). It is however quite unclear how this market can grow. While the literature reveals a lot of interest in technical aspects of the CBE, the social reasons why the market for biobased products remains small have hitherto received little attention. Stakeholder involvement has often been put forward as a useful addition to attend to the social aspects of innovation. An evaluation of several CBE initiatives around the world explained, for example, that lack of community involvement prevented successful take-up (Winans et al., 2017). Other studies argued that different stakeholders need to be involved in the transition, such as collectors and processors of biomass, designers of the bio-based products, as well as envisioned end-users and members of the general public (Inigo \& Blok, 2019; Pyka, 2017; Schlaile et al., 2017; Zwier et al., 2015). Studies such as these support the involvement of stakeholders to attend to the social aspects of the transition towards a CBE. These studies, however, often do not make clear how stakeholder involvement can help to change current market relationships.

In this article, we attend to this gap. The questions we aim to answer in this article are: what value could stakeholder involvement bring to the CBE transition? And are there special requirements that successful stakeholder involvement should meet when it is to support transitioning processes towards a CBE? To answer these questions we reflect on stakeholder involvement literature as well as on our own experiences (by $\mathrm{ACH}$ and $\mathrm{GO}$ ) in six workshops in the Netherlands, which were part of the European H2020 Collective Action project BIOVOICES. BIOVOICES aims to involve all relevant stakeholder groups in the development and delivery of the bioeconomy; including industry players, public policy authorities, researchers and civil society players (see http://www.biovoices.eu). While we initiated the workshops based on reasons that are often provided for stakeholder involvement in research and innovation projects, the results they provided made us reflect on how these could be improved in the future to foster the transition towards a CBE. The aim of this article is to present these ideas in order to enable other researchers to successfully involve stakeholders in the future. In the following, we will first describe arguments for stakeholder involvement found in the literature about responsible innovation and question if these express sufficiently what we are after in market transformations, which are at the heart of the transformation toward the CBE. While markets can be understood in many different ways, we argue that a network perspective to markets, instead of a channel perspective, offers a promising entry point to reflect on a fruitful role that stakeholder involvement could play for the transition to a CBE. Next, we present examples of our own stakeholder workshops that demonstrate this argumentation. In the conclusion we answer our questions and argue that for stakeholder involvement to be truly supportive of CBE, it should attend more to current dependencies between market players and address those responsibly. 


\section{Arguments for Stakeholder Involvement}

The CBE is not the only domain where involvement of stakeholders is suggested. In many domains of innovation, involvement of stakeholders has been proposed to improve acceptance and uptake of (technological) innovation, such as in nanotechnology and genomics, information technology and artificial intelligence (AI) (Bowman \& Hodge, 2007; Grieger et al., 2012). Stakeholder involvement is for example a central part of what is called Responsible Research and Innovation (RRI), which is concerned with the question how innovations can be realised responsibly by letting societal stakeholders reflexively evaluate its societal impacts (von Schomberg, 2013). The involvement of stakeholders is one of the ways to explore societal impacts as well as to reflect on their desirability while innovations are still in the making. This allows developers to become aware of the values and norms at play in stakeholder's evaluation of the societal aspects of their (intended) product and take this into account during the innovation process, which is expected to lead to better, more acceptable innovations and ease the eventual acceptance of these innovations.

A variety of approaches to RRI are available (Blok, 2019). Most commonly these approaches include at least four elements: anticipation, inclusiveness, reflexivity and responsiveness. Anticipation requires that societal impacts are explored ahead of time. Inclusiveness requires that different (societal) actors are included, including also citizens or end-users that usually have no role in innovation. Reflexivity demands that specific effort is done to enhance the reflection of stakeholders, inspiring them to consider the innovation from different angles by engaging them in dialogue with others. Responsivity demands developers of the innovation to take into account the viewpoints of other (societal) stakeholders. Some authors include more than these four elements, some less, but they all contribute to a common goal; which is, to broaden and enrich the perspectives of the makers of technological innovation (including scientists, technicians, businesses, and sometimes policy makers) to help them make decisions that take into consideration the societal aspects of innovation. Generally there are two types of reasons to do RRI and take the step to engage stakeholders in innovation processes, i.e. normative and co-design arguments.

The most important normative argument is perhaps that stakeholder involvement is to enhance the democratic legitimacy of research and innovation. As science and technology are recognised to be world-shaping forces, it is considered important that not only experts decide about it, but also other stakeholders, including end-users and (broader groups of) citizens (Attar \& Genus, 2014; Entwistle et al., 1998; Tomkiv et al., 2017). This is perhaps also the most important argument to involve stakeholders in the transition towards a CBE. As said, the CBE starts from visions of new economic systems that will impact the lives of all actors in that economy, such as input suppliers, producers and consumers (Blok, 2020; Murray et al., 2017; Zwier et al., 2015). As this is a transformation with strong societal, ethical and political relevance, establishing the democratic legitimacy of such transformations seems to be crucial. Limited attention for the normative dimension of CBE has therefore rightfully been diagnosed as one of the obstacles to the realisation of a CBE (Blok, 2020). 
Another argument for stakeholder involvement is that this enables co-design of research and innovation. Examples of such co-design trajectories are the Rondeel system for egg production (Rondeel chicken-farms), where stakeholders contributed to the design trajectory using a reflexive design approach (Bos, 2008). Co-design with stakeholders is expected to contribute to better results, because stakeholders are more aware of their own needs, values and wishes and how proposed innovations (fail to) meet them (de Wit et al., 2013). Alternatively, designers of innovation also become more aware of end-user's values, experiences and knowledge, which allows to attune the innovation more to the demands of end-users. It is expected to make the resulting innovation more relevant, more usable as well as more acceptable and/ or valued (Boenink et al., 2018).

There is, however, a difference between stakeholder involvement in (transformative) technology development that aims to improve for example health care, mobility or production methods and stakeholder involvement in transformations towards a circular biobased economy. Transformative technologies usually promise benefits in the daily life of stakeholder groups in the future, but this is not always the case for innovations that aim to make human (social) life more sustainable. These types of innovations are about replacing well-functioning technologies and practices that are not sustainable in the long term as they pollute our planet, but they are not expected to bring about change that stakeholders will immediately experience as beneficial. It is for this reason that perhaps stakeholder involvement should be ascribed a slightly different role in sustainability transformations than in other innovation trajectories. To our knowledge, this different role has not really been explored in the literature until now.

\section{Reflecting on the Potential Value of Stakeholder Involvement in CBE Transformations}

There is already quite some experience with stakeholder involvement in the context of a specific CBE transformation: the renewable energy transition in Europe. For example, a large-scale public participation programme about the energy transition (Energiewende) took place in Germany (Holstenkamp \& Radtke, 2018). Another example is a co-design tool that was applied in six European communities to better incorporate the perspectives of local citizens into the planning and implementation of local energy transition pathways (Lennon et al., 2019). Authors of these experiments argue that such a participatory action research is important because the energy transition will have "its winners and its losers, both economically and in terms of social justice and community cohesion" (2019, p.1) and they showed that citizens expressed having restricted agency and "felt locked in to a limited set of false choices" (2019, p.1). Allowing stakeholders to get involved is thus expected to give them a sense of co-responsibility and freedom to choose. In addition to public participation, stakeholder involvement is important in sustainability transitions to identify risks (van Vliet et al. 2020). This study found that "stakeholders from business, government, NGOs, and others supplied some $40 \%$ of these risk inputs, significantly widening the scope of risks 
considered by academics and experts" (2020, p.400). Therefore they argue that "impact assessment modelling should be complemented with qualitative research and active stakeholder engagement" to increase the chance of a sustainable transition (2020, p. 400). Similar reasoning can be found in Breukers et al. (2014), who conclude that combining participatory stakeholder dialogue with system analysis enables innovation systems research to also explore the normative dimensions of sustainability innovations.

A system or risk analysis are ways to explore the diverse change-resistant dynamics in current (technology enabled) practices, institutions and infrastructures, which are often referred to as the 'regime level' of innovation. These may seriously hinder sustainability transformations. Examples of change-resistant dynamics include vested economic interests, established routines, rules, dependencies and existing technical and digital infrastructures (Fresco et al., 2021). Regimes are often called 'dominant' as they refer to a whole balance of actions and social interactions, supported by institutions, policy and technology, which are attuned to each other (Geels, 2002). In innovation processes these regimes need to be taken into account: attention has to be paid to phasing out the non-sustainable technologies, materials and practices embedded in regimes (Loorbach et al., 2017).

To tackle resistance to change at regime level, some argue that an encompassing change in the normative standards is needed, which includes and supports the decisions of all actors (Blok, 2020). Many transformation barriers would be lifted if norms would change so that production and consumption was only accepted if this respects the carrying capacity of planet Earth, instead of framing CBE within the current market and economic logic. CBE practices are too often "framed within the market or economic logic and miss the normative dimension of the call for circularity" (Blok, 2020, p. 3). Efforts focus on innovative product development, which limits the production of new circular bio-based products to those that are "economically viable and for which a business case can be made" (Blok, 2020, p. 3). As this leads to limited progress in the effectuation of the transition, Blok argues that what is needed is to set normative standards and get the market to respect those.

Suggestions such as these are thought provoking and seem to suppose an opposition between different norms, which are sometimes referred to as offering different logics. Some authors speak about a market logic such as Runhaar et al. (2020) who distinguish between market logic, sustainability logic and cultural identity logic. The market logic in their view aims for profits: this market "(..) logic is strongly export-oriented and aims at maximising production (..) whilst minimising costs. (..)"(Runhaar et al., 2020, p. 146). Profit is also the primary focus of markets according to Fuenfschilling and Truffer (2014) who argue that "the market logic is generally characterized by principles such as efficient trans-actions in the market place, share price, shareholder activism and self-interest". While Blok (2020, p. 4) recognises that the transition to a CBE is multidimensional and "involves a combination of economic, social and environmental logics", he also states that "current practices in the CBE are dominated by the market logic", because economic gains and losses play a key role in people's motivations to make the transition or not.

This distinction between a market logic and other logics such as a sustainability logic or a social logic triggered us to reflect on the role that stakeholder involvement 
can play in the realisation of a CBE. During involvement activities, stakeholders are usually invited to reflect on socio-cultural dimensions of a CBE, on individual and shared values, understandings and meanings. Markets rarely come forward as part of that social world where meaningful human social interactions and relationships are shaped and sustained or altered. Stakeholders are usually asked about their values and preferences but the market concept is left untouched, as if markets have their own dynamics outside of the realm where actors make sense of and engage in interaction.

Markets are however arenas where people display interactive behaviour and can therefore also be considered as part of the social world (Diaz Ruiz, 2012). A review of theoretical approaches to markets from marketing and sociology of markets suggests that what previously mentioned authors call the market logic resembles most the classic approach to markets as interactive contexts where individuals act on rational preferences and aim to pay the lowest price and get the highest benefits (Diaz Ruiz, 2012). There are however also different market concepts available, which allow to appreciate more the social complexity of markets, understanding them as historically rooted and institutionally embedded interactions which give rise to values and orientations for action as well as access to material resources and social rewards (such as status, a salary, consideration). Network analyses of markets offer a particularly interesting perspective, as they help to analyse the interactive mechanisms that serves to stabilise markets, as well as field analyses which reveal how subjective actors conform to established market conventions (Diaz Ruiz, 2012, pp. 62/63). Approaches such as these allow to look at markets as an integrated part of socio-cultural life and meaning-giving activities and allows to perceive the transition towards a CBE not as just bridging a gap between separated social and market logics, but an encompassing multidimensional social and institutional transition which touches on historically embedded activities and values which provide orientation in people's daily lives and planning. In these networks the actors are like nodes and the threads are trading relationships. What this allows us to see is that what matters in market interactions, is the relevance of the relationship between the seller and the active buyer. Activities of actors in such a network cannot only be understood as aiming to compete with each other to get more profit, or to pay the lowest price: they also seek stability and security, as they depend on each other to provide them good, reliable inputs, semi-finished products or, eventually, end-products. Given these dependencies, people in markets do not always seek to maximise benefits, but they also tend to act prudently and avoid risks and harms, or avoid breaking the trust of suppliers or buyers in them.

Such a network approach to what a market is offers a more complex and dynamic perspective to the role of markets in transitions towards a CBE. While network perspectives have been quite common to look at the socio-technical innovation trajectories, usually markets are considered as one element in this network and they have not been unpacked and problematised a lot. As for example Geels, who developed a multilevel perspective to socio-technological transformations mentions, "Markets are simply assumed to be out there. For radically new technologies, however, there are no established markets and no fixed preferences" (Geels, 2002, p. 1259). The transition needed to make new technologies part of social life, involves therefore 
also a change in the market. But it is - to our knowledge-rare to unpack the market concept itself in reflections about the transition to the (circular) bio-based economy and uncover the social dynamics that underlie it. An exception is Schanz and coauthors who use it to analyse current markets to find leverage points to transition towards a bio-based economy in a systematic manner and focus on the German bioeconomy (Schanz et al., 2019). But it has, to our knowledge, not been used yet to come to a better understanding of the role that stakeholder involvement can play to support such a change. The perspective Schanz et al. offer to markets in innovations, however, give reason to think that it can play a very interesting role.

According to Schanz et al. the role of markets in the transition towards a biobased economy is often understood in a too simplistic way; either markets are considered the endpoint of innovation trajectories, or at the beginning, when innovation is understood in a linear or channel-like manner. In this channel the provision of input materials (such as innovative bio-based products) is linked via several transformative changes to outputs (such as changed consumer behaviour) that stand for change. The dynamics of change will then either start with the development of raw materials downstream up to the production of a consumer result, or it goes in the opposite direction starting upstream with a different demand from consumers to the development of new materials downstream. A network perspective to markets, according to Schanz et al. allows to see more of the complex social dynamics that change requires, including some of the resistances that may be encountered to change at the level of markets. A successful transition towards a bio-based economy depends on the one hand on the networks that lead to the development of new (bio-based) products and which aim to create new or reconfigure old value chains, and on the other hand on communities of consumers which Schanz et al. characterise as being quite resistant to change. In between these two is the market system dynamic, which is co-shaped by the other dynamics. All these interconnected networks, Schanz and colleagues observe, have a tendency to resist fundamental changes, as actors' actions in all of them are characterised by "a general quest for stability and security" (Schanz et al., 2019, p. 146). Choices of individuals depend to a large extent on dynamics in the communities, but also on the values and historically embedded rules and arrangements at the market systems level. Schanz et al. quote Walker saying that: "[t]he firms in the industry recreate a stable network structure whose foundation was laid at an early point in the industry's history. Firms' early partner choices thus have a significant impact on the course of future cooperation" (Schanz et al., 2019, p. 147).

In the analysis that Schanz et al. offer, this very complex, layered perspective to the market is used to analyse what are the appropriate entrance points to start to change towards the German bioeconomy. They are not particularly interested in the topic of stakeholder involvement. We think however that a network approach such as the one offered by Schanz et al. gives a useful insight into the purpose and function of stakeholder involvement in contexts of transitions towards a CBE. Stakeholder involvement allows to study the norms and values of groups of stakeholders (such as consumers, policy makers, businesses), their needs and the conditions under which they would accept a new technology, but they can also enhance participants' reflections about their (mutual) dependencies, their desire for stability and security within 
the various (interconnected) collaborations in which they are involved, including the path dependencies that point towards historically rooted trusted relationships that they seek to perpetuate and that cause them to resist too encompassing changes. Perspectives on markets as layered networks, which allow to look at relationships and dependencies they bring about between people, companies and (research or policymaking) organisations are-to our knowledge-not yet forefronted in stakeholder involvement activities. The normative argument for stakeholder involvement or the co-design argument both seek to bring developers and users of technology closer together, but neither of them considers the more complex dynamics in which actors along the value chain depend on each other, including also the consumer. Involving stakeholders can however allow to develop a better insight into these dependencies and the motivations and values they bear with them and which resist change. We think this will offer a better understanding of the reasons why some stakeholders do not (yet) take the necessary actions to change towards the CBE and develop better, more responsible, strategies to support them to make the transition.

In our view, stakeholder involvement workshops can play a very different role in the realisation of a CBE, which has hitherto not received a lot of attention: they can help to acquire insight into dependencies in the market and-if workshops are appropriately shaped - they offer an opportunity to connect people to develop appropriate responses to them. It is this perspective to the role of stakeholder involvement in a responsible transition to a $\mathrm{CBE}$ that we want to explain and argue for, based on limitations we perceived of our own workshops in the Netherlands that we have done for the project BIOVOICES. While we do not believe the results of these workshops offer particularly new or surprising insights for people working in the field, we do think they reveal market dependencies that hamper a CBE transformation. By looking at the results through the lens of a network perspective to markets, the historically rooted market systems that created interdependencies between people, businesses and other organisations in markets become visible. It seems to us that this dimension deserves to be taken into account more in future stakeholder workshops on the transition to a CBE (see Table 1). Therefore we reflect on our experiences with executing the six stakeholder involvement workshop for the CBE transformation and explore which market perspective guided the set-up and which dependencies between stakeholders in the market were articulated.

\section{Innovation Challenges of Bio-Based Pioneers Guided the Stakeholder Involvement Workshops}

For the workshops we focused on two kinds of bio-based applications relevant for the project BIOVOICES: bio-based building materials and bio-based packaging. These concrete and tangible topics about products that people can touch and experience daily make it easier for participants to develop and share ideas, opinions and reactions (Hoes et al., 2018).

As soon as the topics where clear we searched for inspirational speakers about bio-based building and bio-based packaging that could inform and engage the 
Table 1 Market transformation perspective for the bio-based building and bio-based packaging

In the literature the transformation of the current fossil-based economic system to a CBE is described to mean that alternative bio-based niche-markets have to become mainstream, which implies breaking through and becoming part of the regimes of various established sectors (Verbong \& Geels, 2007). This transition is often understood in a way similar to the channel image that Schanz et al. describe: starting downstream, the transition will then require developing new kinds of products and the success of these products on the market relies heavily on implementation efforts by existing and new businesses (Murray et al., 2017). Currently, many of such bio-based alternatives are available on the market for energy, fuels, (food) packaging, construction, furniture, clothing/textile, cosmetics, toys and other commodities (Molenveld et al., 2015; Overbeek \& Hoes, 2018; van Dam \& van den Oever, 2019). However, at present the availability of these alternatives have not led to breakthroughs in the packaging sector and the Dutch building sector. Other studies focus upstream in the channel and start with motivations of the general public and reveal that there is low public awareness about bio-based products (Sijtsema et al., 2016). Therefore, consumer pressure towards businesses to replace fossilbased materials with bio-based alternatives is generally low, which is also considered a reason why brand owners are less eager to invest in bio-based products (Pfau et al., 2017). Surveys indicate that only $12 \%$ of the respondents have ever consciously chosen bio-based products over conventional ones (Pfau et al., 2017). An explanation for this is that informed consumers expect limited personal benefits from bio-based products in terms of better performance or reduced price (Meeusen et al., 2015). This is problematic for mainstream consumption of bio-based products as purchasing decisions are greatly influenced by expected improvement of value and low prices of the product

The literature usually starts from a linear perspective to innovation (the classic channel metaphor) and points out that lacking consumer demand on the one hand and lacking investments from businesses on the other hinder the development of the new markets that the transition to a CBE needs. To overcome these obstacles, some argue that governments should step in and promote the CBE more (Ahlheim, 2018). Some authors argue, however, that it is hard for democratic governments to support developments toward the CBE, because it is difficult to reach consensus in complex and morally laden developments such as about whether, to what degree and how to stimulate the economy towards a CBE (de Olde \& Valentinov, 2019). As there are many disagreements about the question whether specific bio-based products actually contribute to realizing a bioeconomy that is truly circular, policy makers also disagree about what policy should be adopted (European Commission, 2019). In the channellike perspective to innovation of markets, it is quite difficult to find a way out of this impasse. In the absence of businesses who are willing to invest, lacking informed and committed consumers who demand bio-based products and without political consensus about the value of government support for $\mathrm{CBE}$, it is quite unclear what can be done to foster change. But as there are other perspectives to markets available, such as a network perspective, it can be worthwhile to use this as an analytic lens to look at resistance to change and develop an appropriate response to it. It helped us to see what was missing in the approach we chose in our own workshops

workshop-participants. We involved bio-based pioneers, not only to participate as speakers but also to figure as problem owners who are able to put their innovation challenges forward as a topic for conversation with the participants. We believed problem owners could bring the topics of the transformation challenge to life for a diverse audience and create a sense of urgency, energy and group-connection/feeling. Furthermore, we thought that conversation about the transformational challenges that the problem owners encounter, would increase the potential impact of the workshops. We assumed it was more likely that workshops would lead to follow-up activities, if core challenges of these problem owners would be addressed by participants during the workshops. To us it seemed this would be engaging for participants and it would invite them to consider the conditions for the acceptability of the transition as well as take part in its realization.

The problem owners that we chose were innovators with differing institutional backgrounds as well as policy makers. Several problem owners were entrepreneurs 
with downstream start-ups that provide bio-based building materials and seek ways to expand their clientele upstream (such as in the case of bio-based building). For biobased plastics, we chose a bio-based business developer as a problem owner who works for established multinationals that offer bio-based and fossil-based plastics to their clients (bio-based packaging). We also involved local policy makers as speakers and participants in our workshops, who try to stimulate the transformation toward the $\mathrm{CBE}$ in their region in an effective way and encounter challenges in the process.

In each workshop between 15 and 55 people participated; workshops took roughly $2 \mathrm{~h}$ and started with four short plenary presentations by the problem owners. After that, subgroup conversations and brainstorming took place in which participants explored a set of questions. (Hoes et al., 2018).

In hindsight our assumptions about the value of using bio-based pioneers (start-ups) as entry point for stakeholder involvement workshops was partly correct. In our opinion, involving pioneers brings an attractive programme that resulted in relatively high numbers of participants of diverse stakeholder groups. In addition, lively conversations took place and participants were engaged in an enthusiastic way. We assume that this was realized due to the tangible examples and the underlying desire to help these pioneers in their innovation quest.

On the other side, we are also critical about the actual impact of our workshops. During the workshops relevant and tough bio-based innovation challenges were addressed by participants that, in our opinion, deserved more thorough exploration with incumbent market stakeholders that were marginally present at the workshops. While we were unaware of it at the time, it seems that the BIOVOICES workshops started more from a channel perspective to market innovation than a network perspective of markets. For example we invited bio-based pioneers (such as start-ups) as speakers and their innovation challenges was the central topic of the conversations, apparently assuming that innovation starts with the makers of new products that subsequently have to conquer the market. If we would have started with a network market perspective when organising the workshops, much more energy would have been put into involving key incumbent market players. Below we illustrate these considerations by presenting the market dependencies for bio-based building and packaging in the Netherlands that were brought forward during the stakeholder involvement workshops and which, looking back, we think we should have given more attention during the set-up of the workshops.

\section{Bio-Based Building Workshop Results: Market Dependencies and Culture that Hampers CBE Transformation of the Dutch Building Sector}

Workshop participants brought forward numerous obstacles within the Dutch building sector that hamper the wider adoption of (novel) bio-based building materials (see Table 2). For example, the established routines of Dutch housing construction which are characterized by task division, specialisation and dependencies between professionals and businesses make it difficult to try out new materials. In the Netherlands most homes are built using mass construction principles: entire neighborhoods with similar houses are designed, planned and developed simultaneously. The large 
building sites are supervised by professional property developers and executed by various specialized builders who contribute to the collective machinery of organisations and businesses constructing homes and each one of them has to respect strict protocols and meet preset time frames.

Moreover, to guarantee a minimum standard for the safety, health and comfort of houses, there are numerous building regulations that need to be followed. Regulatory building requirements include structural and mechanical integrity, fire prevention and energy conservation. Permissions to build are only granted if the building plans convince local governments that building requirements are met. These regulations protect consumers and citizens from unsafe houses but they can also create a barrier for new bio-based building materials to enter the market. For example, a participant explained that the norms create an unfair level playing field between biobased and non-bio-based insolation materials. It is argued that the moist ventilation feature (damp-open) of bio-based isolation does not impact the isolation quality, as they function as a woolen sweater, but current building norms do score bio-based damp-open insolation lower than their fossil alternative that have no moist ventilation. Moreover, it is understandable that property developers are hesitant to try out or use novel insolation materials that have not yet survived the test of time. The insolation capacity of houses is becoming more important in the current energy transition and it is very difficult and costly to reverse/change the used insolation material

Table 2 Quotes from workshop participants that illustrate perceived dependencies in the building sector

In our workshops we found plenty examples of people who brought forward their own and other's limited power to change the market

Many people brought forward problems related to resistance of other stakeholders to new products, which limits their own possibilities to choose bio-based building materials

- 'Contractors are hesitant, or even decline to build with (new) bio-based products. They say No. I have never done that. I can do it as I always do and with cheaper products. And by lowering their costs for the building materials they make more profits'

Many participants also brought forward underlying issues that explain these change resistant behaviors of contractors that hamper the transition towards the $\mathrm{CBE}$

- 'The main problem is the risk for high (labour and relational) costs related to having to remove and replace building materials that are installed into a house a few months or years after its completion'

- 'Apparently the bio-based producers have not yet achieved the level of trust and reassurance of builders that allows them to feel that all will be all right if they use novel bio-based building materials.'

Participants considered solutions to share the risks of using new bio-based building materials. In this way that want to overcome uncertainty about the quality and durability of the materials which they are reluctant to sell to the clients (the building companies) who rely on them to provide good quality work

- 'The government should create a fund for bio-based materials so that we collectively offer a 10 or 15-year guarantee on these material to stimulate the development of the bio-based building market.'

Participants mention that the building system is organized in such a way that it hampers innovation in the Netherlands

- Architects are quite aware and positive about bio-based materials, but for the realization they are dependent on the actions of the contractors and project developers who have a final say in the Netherlands, as architects are not held responsible for the completed houses, but contractors are'

- 'And in the Netherlands, home-owners have little influence over the used building materials as only a small minority commissions the construction of a house. Most [people, $\mathrm{ACH}$ ] buy completed houses provided by property developers or [other, $\mathrm{ACH}$ ] home-owners' 
after the completion of the house (creating a lock-in). As building contractors are accountable for attributable construction defects (shortcomings) after the delivery they have to be certain that the material will perform for decades. These aspects explain the prudent attitude of actors working in the building regime.

The participants of the workshops proposed multiple actions that could contribute to creating conditions in which new relationships with bio-based materials could be formed to transform the current building sector towards a CBE. It was mentioned that local, regional and central governments could act as a launching customer of (new) bio-based building materials for their (new) public buildings (green public procurement). This way the risks related to using new building materials and techniques could be shared at public level, instead of charging individual citizens or companies with the early adopter's costs and risks. Moreover, governments could finance researchers who can monitor the performance and customer satisfaction of these bio-based solutions over a longer period of time. It was also argued that governments have to invest in the development of a more steady and high-quality stream of promising crops and processing facilities to kick-start the bio-based economy. Furthermore, it was argued that trainings should be provided for people working in the building sector so that they can learn how to build with these (new) bio-based building materials.

These types of actions could further develop the bio-based building market, allowing the diverse actors to develop trust in their quality and reliability. Based on the network perspective to markets, it is possible to understand why this may be effective: it is important for actors at the regime level to spend time developing trusted relationships between producers and clients of biobased building materials, as well as to develop trust in the products themselves. Such relationships demand continuous care and demand that providers of new biobased building materials do not put clients at risk. Government's interference to support to start working with bio-based materials in public buildings can be successful too, as this allows to experience the performance of the products and will make other clients feel more confident to use it as well. Alternatively it will also make the sellers of these products more confident, as they know they can deliver it to their clients without putting them at risk. Participants in the workshops also articulated the ideas that municipalities impose the requirement that bio-based buildings have to be constructed on new offered building terrains. In addition, in the Netherlands permission has to be asked from local governments to start building, called the Environmental Performance of Buildings format, which can be used as a policy instrument to stimulate the usage of bio-based building materials. This can be done by decreasing the maximum level of greenhouse gas emissions permitted in the building plans or by making bio-based materials more attractive in the calculations for the environmental assessment. It was also argued that more Life Cycle Analyses of bio-based building materials and non-bio-based building materials are needed to justify these policy options and to develop trust of the building sector in these materials. 


\section{Bio-Based Packaging Workshop Results: CBE Transformation Depend on Changes in the Waste Sector}

Different dependency issues were brought forward by participants that joined the bio-based packaging workshop. An issue that was discussed, for example, is that the value of bioplastic packaging depends a lot on what happens at the end of the lifecycle; that is, after the plastics have been used to package food and are being disposed. Participants identified obstacles related to the reuse and recycling of bioplastics. Although technical waste processing options for bioplastics are available, these are not yet adopted by the waste sector and therefore bioplastics are currently treated as residual waste. In the Netherlands this means that they are predominantly burned, which basically denies the added value for the environment that bioplastics were supposed to have.

During the workshop it was explained that form-fixed bioplastic packaging (e.g. bottles) can be recycled and bioplastic films (such as candy wrappings) can be composted industrially. However, these options are not offered by the waste facilities as the mono-streams of bio-based packages are too small. The waste sector considers it too labour intensive (and expensive) to separate the bioplastics from the rest of the waste and the resulting mono-stream is too small for the waste processing industry to process it (cost-) effectively. In addition, the business model for the waste industry to compost bioplastic is weak as it does not result in input products that can be sold (such as compost, or raw material for new plastic products).

The participants of the workshops said that more cooperation in the packaging value chain is needed to develop and spread sustainable reuse and recycle solutions of bioplastics, and that priority has to be given to interactions between the bioplastics producers and the waste sector (see Table 3). Another challenge for such a cooperation is that waste processing is done regionally and that processing facilities and collection approaches differ to some degree. Currently, the producers of bio-based packaging materials have little influence over waste processing practices. The Dutch government is now considering to make the producers of (bio-based) plastic packaging more responsible for the sustainable processing of the products that they bring to the market. A practical reason for this is that multinationals have the power and capital to invest in such a change. A normative argument is that it is fair that producers take into account the life cycle of their products and do not pass on the costs of environmentally friendly disposal to others. Doing this is however a new responsibility for these multinationals and it is questionable whether they are willing to accept it, as it is usually the responsibility of waste processors.

Another strategy that was discussed during the workshop was to start with small mono-streams of bioplastics to allow the waste sector time to get more experience with the recycling of bioplastics. Moreover, starting small was seen as a way to overcome the innovation dilemma of investing in large scale bioplastic waste management that could not yet be used to process a small stream of bioplastics. It was also seen as a way to prevent needing to invest in the production of larger quantities of bioplastics that are currently not so environmentally friendly due to the absence of a good waste management strategy. During the brainstorm with participants in 
Table 3 Inputs from workshop participants that illustrate perceived dependencies in the packaging sector

In our workshops we found plenty examples of people who brought forward their own and other's limited power to change the market

Participants considered the difficulty that bioplastics lose their sustainability potential if their reuse, recycling and composting is not well organised

- 'Bioplastic are currently not recycled or composed well as the waste streams are too small to process'

- 'There is high uncertainty among consumers how to dispose bioplastic packages: in the green, plastic or grey bin?'

- 'How to contribute to more re-use of plastics? From a circular economy perspective it is better to reduce and reuse packaging instead of recycling or composing them'

Participants considered solutions for the disposal problem at waste collection and waste management level

- 'There are many places where big quantities of mono-streams of bioplastic waste can be created and collected. This could then be sent to waste facilities that want to expand their experience [dealing with this waste, ACH]. Let's start with soccer stadiums, amusement parks, zoos, fast food restaurants and in-flight meals'

- 'A national waste management approach should be developed, so that regions have comparable waste systems. This makes it easier to organise cooperations and agreements between producers and the waste industry'

Participants also considered changing norms and consumer behavior

- 'In Japan people do not eat on the street or in public transport as it is considered impolite. If we would ban eating on the street or in public transport, the need for packaging and disposable plates and cutlery will decline'

- 'Reward consumers who reuse or return products'

- 'If the amount of [permitted, $\mathrm{ACH}$ ] household waste was restricted, this would trigger consumers to choose products with less packaging, which would trigger food companies to reduce the amount of packaging'

our workshops, diverse locations and events were mentioned as opportunities for experimentation, such as festivals, events, theme parks, restaurants and other catering where large quantities of mono-streams can be created and collected. It was also proposed to simplify the labelling of bioplastics by, for example, giving all bioplastic packaging a blue colour, which would help consumers to sort their waste. Others argued that it is too difficult to make consumers realise good separation of waste streams and suggest instead to focus on better sorting techniques at waste facilities with new technologies such as Near Infrared (NIR) systems.

\section{Concluding Reflections}

In the beginning of this article we asked two questions: what value could stakeholder involvement bring to the CBE transition? What are special requirements of successful stakeholder involvement in transition processes towards a CBE? Based on our reflections on the literature on stakeholder involvement and on market concepts, as well as on the results of our stakeholder workshops carried out in BIOVOICES, we conclude that stakeholder involvement is especially useful for a 
CBE transformation if it provides insight into the dependencies between players in the market that hamper the transition. Recently, more sustainability transitions scholars started to write more about the importance of developing a better understanding of market formation to realize upscaling and diffusions of innovation. It is argued that transition studies paid too little attention to market formation (Boon et al., 2020). A focus on markets is however rare in this literature. Most authors focus on different aspects needed to bring about regime change, but they do not focus on the market as an entry point (Brown et al., 2013; Köhler et al., 2019; Loorbach et al., 2017).

We argue that to realise change, it is more fruitful to start understanding the market as an area of meaningful human interaction (Diaz Ruiz, 2012), with players who have complex and layered reasons to act as they do (Schanz et al., 2019). This perspective differs from the channel-like perspective to innovation of markets (Schanz et al., 2019) that puts a lot of responsibility on the shoulders of start-ups and early adopters to realize the transition towards the CBE. The presupposition behind this approach is that the transition depends on new innovative products, which will gradually conquer the market, first by attracting the interest of early adopters and eventually also larger established companies and consumers at regime level. While this approach to innovation may have been the case for innovations that offer a clear benefit to the users within an established network of market dependencies, such a linear model of innovation is not likely to be realised for bio-based novelties, as these innovations bring benefits for future generations but not per se for the early adopters. In addition bio-based novelties bring risks within present market dependencies. We propose to exploring these risks and dependencies more carefully to transition towards a CBE.

Stakeholder workshops can provide an opportunity to open-up the black-box of markets and see the dependencies, norms, and routines that hamper innovation. Seeing the market as an area of meaningful human interaction (Diaz Ruiz, 2012), with players who have complex and layered reasons to act as they do (Schanz et al., 2019) helps to explore ways in which market players can change more 'responsibly'.

This adds an extra value and purpose to stakeholder involvement in the context of the transition towards a CBE. While stakeholder involvement is usually proposed as a way to enhance democratic legitimacy of innovation, as well as to realise co-creation of innovative products and procedures which is thought to enhance uptake (Attar \& Genus, 2014; Tomkiv et al., 2017), we propose that stakeholder involvement also offers a unique occasion to explore market dependencies and deal with them responsibly, without putting stakeholders too much at risk.

When considering dependencies in the present market, it is not surprising that players at regime level prefer to produce, process and/or use conventional rather than bio-based products. The CBE transition is risky for established businesses, not only because it may cost them money, but also because they have established a good reputation towards their clients which they can lose if they start selling products with an uncertain quality, durability or delivery time. If they would start selling products that they feel uncertain about, this will make them unreliable -and therefore irresponsible- business partners. 
To foster established companies and businesses' capacity to change it is not enough to educate them, to enhance their awareness of and reflection about needs and values of end-users, nor is it sufficient to create more support for the normative basis of a CBE or ask for policy that implements it. To get them on board in the innovation trajectory, they should be supported to gradually develop trust in the products and change the market relationships in which they are involved. Our experience illustrates that strategies to achieve responsible market transformation can be explored during stakeholder workshops. During these workshops, stakeholders should be invited to share the reasons why they resist change and ideas can be explored for gradual, prudent change which attend to needs and dependencies. An option could be, for example, to experiment with new bio-based products next to the continuation of the use of well-known traditional non-bio-based materials: in this way stakeholders are offered the opportunity to monitor the performance of the new biobased products in comparison to the traditional non-biobased ones. This allows to provide proof of the quality of the biobased product and it allows producers as well as clients to get used to it and experience its reliability and durability, before actually having to invest in it heavily.

As we look back on our workshops, we think they were perhaps first and foremost a useful occasion to identify market dependencies. Now that we know these dependencies better, however, we would have chosen to do the workshops in a different way. If we would do the workshops again, we would include more participants who work for established businesses (the so-called 'regime players'), rather than startups. Ideally, market dependencies should be explored prior to stakeholder involvement sessions, by means of a literature study and/or interviews with stakeholders. After dependencies have been identified, relevant market stakeholders can be selected and involved in workshops that aim to develop strategies to realise responsible CBE market transformation. To realise open exchange of ideas we recommend a small group size and avoidance of inclusion of market competitors. Furthermore, it may be advisable to commit to keep everything said during the workshop confidential in advance.

For our biobased building workshops we invited regime players at market level multiple times, but we did not get them on board. In hindsight, the setting of our workshops were probably more appealing for biobased start-ups then established businesses. Start-ups are often CBE believers and are a more motivated to realise it than established companies and businesses (Köhler et al., 2019). The business of the start-ups depends on the realisation of CBE and they do not have a lot to lose in the present non-biobased market since their success in it is modest. Stakeholder workshops provide an opportunity for start-ups to pitch their ideas and grow their reputation. The value for participation for established businesses is however less straightforward. To get established businesses on board, it is perhaps better to show understanding for their concerns and offer support to reflect on gradual ways to realise the transition, while being careful to attend to the needs of the company with respect to its reliability toward clients and its survival towards the future.

Workshops would be most valuable, we think, if they include various stakeholders with which the company that acts at a regime level already interacts in the 
market. In this way, a free space is developed to explore ideas together about how the transition can be made, while attending well to everyone's needs and interests.

As market players rarely sit around the table to talk about the transition toward a $\mathrm{CBE}$, we expect a workshop could offer a free space to start such interactions. This would allow to try find solutions together in a setting that is quite different from the usual market space where their interaction takes place. As we are aware that dependencies may bring about tensions that trigger feelings of uncertainty and loss of control, which can escalate into unconstructive conflict, we argue for a safe environment. This means that perspectives are first explored in interviews, before inviting stakeholders in a workshop together. Such an approach supports a more 'responsible' transition toward CBE, as it recognises and takes into account the needs of stakeholders and avoids putting anyone inadvertently or unduly at risk. This will foster an innovation trajectory that is probably more gradual and slow, but which has more change to be accepted and valued by large companies with an established market position. In the end, therefore, we expect this leads to a more careful, but also a more enduring transition which will eventually have more impact on the economy.

Acknowledgements We thank two anonymous reviewers for reading our manuscript so carefully and critically. It has helped us to substantially improve the manuscript.

Funding This work took place as part of the project 'BIOVOICES'. This project has received funding from the. European Union's Horizon 2020 research and innovation programme under Grant Agreement No. 774331.

Availability of data and materials Yes, but mostly confidential data such as audio recordings of workshops. But also presentations and reports of workshops.

Open Access This article is licensed under a Creative Commons Attribution 4.0 International License, which permits use, sharing, adaptation, distribution and reproduction in any medium or format, as long as you give appropriate credit to the original author(s) and the source, provide a link to the Creative Commons licence, and indicate if changes were made. The images or other third party material in this article are included in the article's Creative Commons licence, unless indicated otherwise in a credit line to the material. If material is not included in the article's Creative Commons licence and your intended use is not permitted by statutory regulation or exceeds the permitted use, you will need to obtain permission directly from the copyright holder. To view a copy of this licence, visit http://creativecommons.org/licen ses/by/4.0/.

\section{References}

Ahlheim, M. (2018). Environmental economics, the bioeconomy and the role of government. In I. Lewandowski (Ed.), Bioeconomy. Cham: Springer. https://doi.org/10.1007/978-3-319-68152-8_10

Attar, A., \& Genus, A. (2014). Framing public engagement: A critical discourse analysis of GM Nation? Technological Forecasting and Social Change, 88, 241-250. https://doi.org/10.1016/j.techfore.2014. 07.005

Boon, W. P. C., Edler, J., \& Robinson, D. K. R. (2020). Market formation in the context of transitions: A comment on the transitions agenda. Environmental Innovation and Societal Transitions, 34, 346347. https://doi.org/10.1016/j.eist.2019.11.006

Blok, V. (2019). From participation to interruption: Toward an ethics of stakeholder engagement, participation and partnership in corporate social responsibility and responsible innovation. Edward Elgar Publishing. 
Blok, V. (2020). The normative and social dimension of the transition toward a responsible circular biobased economy. Cambridge: Cambridge University Press. In press.

Boenink, M., van der Scheer, L., Garcia, E., \& van der Burg, S. (2018). Giving voice to patients: developing a discussion method to involve patients in translational research. NanoEthics, 12(3), 181-197.

Bos, A. P. (2008). Instrumentalization theory and reflexive design in animal husbandry. Social Epistemology, 22(1), 29-50.

Bowman, D. M., \& Hodge, G. A. (2007). Nanotechnology and public interest dialogue: Some international observations. Bulletin of Science, Technology \& Society, 27(2), 118-132. https://doi.org/10. $1177 / 0270467606298216$

Breukers, S., Hisschemöller, M., Cuppen, E., \& Suurs, R. (2014). Analysing the past and exploring the future of sustainable biomass. Participatory stakeholder dialogue and technological innovation systems research. Technological Forecasting and Social Change, 81, 227-235. https://doi.org/10. 1016/j.techfore.2013.02.004

Brown, R., Farrelly, M., \& Loorbach, D. (2013). Actors working the institutions in sustainability transitions: The case of Melbourne's stormwater management. Global Environmental Change, 23(4), 701-718. https://doi.org/10.1016/j.gloenvcha.2013.02.013

Dammer, L., Eder, A., Costenoble, O., Wan, S., \& Briassoulis D. (2015). KBBPPS Deliverable No. 5.3: Market entry barriers. https://www.biobasedeconomy.eu/app/uploads/sites/2/2017/03/Market-entrybarriers.pdf.

De Olde, E. M., \& Valentinov, V. (2019). The moral complexity of agriculture: A challenge for corporate social responsibility. Journal of Agricultural and Environmental Ethics, 32, 413-430. https://doi. org/10.1007/s10806-019-09782-3

de Wit, M., Abma, T., Koelewijn-Van Loon, M., Collins, S., \& Kirwan, J. (2013). Facilitating and inhibiting factors for long-term involvement of patients at outcome conferences-lessons learnt from a decade of collaboration in OMERACT: a qualitative study. British Medical Journal Open, 3(8), e003311.

Diaz Ruiz, C. A. (2012). Theories of markets: Insights from marketing and the sociology of markets. The Marketing Review, 12(1), 61-77.

Entwistle, V. A., Renfrew, M. J., Yearley, S., Forrester, J., \& Lamont, T. (1998). Lay perspectives: Advantages for health research. BMJ, 316, 463. https://doi.org/10.1136/bmj.316.7129.463

European Commission. (2012). Innovating for sustainable growth. A bioeconomy for Europe. https://ec. europa.eu/research/bioeconomy/pdf/official-strategy_en.pdf.

European Commission. (2018). A sustainable Bioeconomy for Europe: strengthening the connection between economy, society and the environment. Updated Bioeconomy Strategy. Retrieved May 15, 2020, from https://ec.europa.eu/research/bioeconomy/pdf/ec_bioeconomy_strategy_2018.pdf\# view $=$ fit\&pagemode $=$ none.

European Commission. (2019). Report on the implementation of the Circular Economy Action Plan. Retrieved May 15, 2020, from https://ec.europa.eu/commission/sites/beta-political/files/report_ implementation_circular_economy_action_plan.pdf.

Fresco, L.O., Geerling, F., Hoes, A.-C., van Wassenaer, L., Poppe, K.J., \& van der Vorst, J. (2021). Sustainable food systems: do agricultural economists have a role? European Review of Agricultural Economics. https://doi.org/10.1093/erae/jbab026.

Fuenfschilling, L., \& Truffer, B. (2014). The structuration of socio-technical regimes - Conceptual foundations from institutional theory. Research Policy, 43(4), 772-791.

Geels, F. W. (2002). Technological transitions as evolutionary reconfiguration processes: A multi-level perspective and a case-study. Research Policy, 31(8-9), 1257-1274.

Grieger, K. D., Wickson, F., Andersen, H. B., \& Renn, O. (2012). Improving risk governance of emerging technologies through public engagement: The neglected case of nano-remediation? International Journal of Emerging Technologies and Society, 10, 61-78.

Holstenkamp, L., \& Radtke, J. (Eds.). (2018). Handbuch energiewende und partizipation. Springer.

Hoes, A.-C., Overbeek, G., Albertini, S., \& Savelkouls, C. (2018). Biovoices Deliverable 3.4 connecting bio-based forces for a sustainable world: Guide for mobilisation and mutual learning workshops. BIOVOICES Deliverable 3.4. Retrieved June 15, from 2020, http://www.biovoices.eu/results/public-results.

Inigo, E. A., \& Blok, V. (2019). Strengthening the socio-ethical foundations of the circular economy: Lessons from responsible research and innovation. Journal of Cleaner Production, 233, 280-291.

Köhler, J., Geels, F. W., Kern, F., Markard, J., Onsongo, E., Wieczorek, A., Alkemade, F., Avelino, F., Bergek, A., Boons, F., Fünfschilling, L., Hess, D., Holtz, G., Hyysalo, S., Jenkins, K., Kivimaa, 
P., Martiskainen, M., McMeekin, A., Mühlemeier, M. S., \& Wells, P. (2019). An agenda for sustainability transitions research: State of the art and future directions. Environmental Innovation and Societal Transitions, 31, 1-32. https://doi.org/10.1016/j.eist.2019.01.004

Lennon, B., Dunphy, N. P., \& Sanvicente, E. (2019). Community acceptability and the energy transition: A citizens' perspective. Energy, Sustainability and Society, 9, 35. https://doi.org/10.1186/ s13705-019-0218-z

Loorbach, D., Frantzeskaki, N., \& Avelino, F. (2017). Sustainability transitions research: transforming science and practice for societal change. Annual Review of Environment and Resources, 42, 599626. https://doi.org/10.1146/annurev-environ-102014-021340

Meeusen, M., Peuckert, J., \& Quitzow, R. (2015). Open-BIO Work Package 9: Social acceptance deliverable 9.2 open-bio acceptance factors for bio-based products and related information systems. Retrieved May 8, 2020, from http://www.biobasedeconomy.eu/research/open-bio.

Molenveld, K., van den Oever, M., \& Bos H. (2015). Bio-based Packaging Catalogue. Wageningen UR. Retrieved April 5, 2020, from http://library.wur.nl/WebQuery/wurpubs/fulltext/343774.

Murray, A., Skene, K., \& Haynes, K. (2017). The circular economy: An interdisciplinary exploration of the concept and application in a global context. Journal of Business Ethics, 140(3), 369-380. https://doi.org/10.1007/s10551-015-2693-2

Overbeek, G. \& Hoes, A.C. (2018). Synthesis of market perspectives to develop bio-based value chains. BIOVOICES Deliverable 3.1. Retrieved December 20, 2019, from http://www.biovoices.eu/results/ public-results.

Pfau, S., Vos, J., Dammer, L., \& Arendt, O. (2017). RoadToBio Deliverable 2.2: Public perception of biobased products. Retrieved April 12, 2020, from http://www.roadtobio.eu.

Pyka, A. (2017). Dedicated innovation systems to support the transformation towards sustainability: Creating income opportunities and employment in the knowledge-based digital bioeconomy. Journal of Open Innovation: Technology, Market, and Complexity, 3(4), 27. https://doi.org/10.1186/ s40852-017-0079-7

Raworth, K. (2012). A safe and just space for humanity: Can we live within the doughnut? Oxfam Discussion Papers.

Runhaar, R., Fünfschilling, L., van den Pol-Van Dasselaar, A., Moors, E., Temmink, R., \& Hekkert, M. (2020). Endogenous regime change: Lessons from transition pathways in Dutch dairy farming. Environmental Innovation and Societal Transitions, 36, 137-150.

Schlaile, M. P., Urmetzer, S., Blok, V., Andersen, A. D., Timmermans, J., Mueller, M., Fagerberg, J., \& Pyka, A. (2017). Innovation systems for transformations towards sustainability? Taking the Normative Dimension Seriously. Sustainability, 9(12), 2253. https://doi.org/10.3390/su9122253

Schanz, H., Federer, J., \& Wilczynski, M. (2019). Markets as leverage points for transformations of economic systems: The example of the German bioeconomy. Environmental Innovation and Societal Transitions, 33, 140-161.

Sijtsema, S. J., Onwezen, M. C., Reinders, M. J., Dagevos, H., Partanen, A., \& Meeusen, M. (2016). Consumer perception of biobased products-An exploratory study in 5 European countries. NJASWageningen Journal of Life Sciences, 77, 61-69.

Stegmann, P., Londo, M., \& Junginger, M. (2020). The circular bioeconomy: Its elements and role in European bioeconomy clusters. Resources, Conservation \& Recycling. https://doi.org/10.1016/j. rcrx.2019.100029

Tomkiv, Y., Liland, A., Oughton, D. H., \& Wynne, B. (2017). Assessing quality of stakeholder engagement: From bureaucracy to democracy. Bulletin of Science, Technology \& Society, 37(3), 167-178.

Van Dam, J., \& van den Oever, M. (2019). Catalogus biobased bouwmaterialen 2019: het groene en circulaire bouwen. Wageningen Food \& Biobased Research. Retrieved November 12, 2019, from https://doi.org/10.18174/461687.

Van den Oever, M., Molenveld, K., Van der Zee, M. \& Bos, H. (2017). Bio-based and biodegradable plastics-Facts and figures: Focus on food packaging in the Netherlands. Wageningen Food \& Biobased Research. Retrieved November 12, 2019, from http://edepot.wur.nl/408350.

van Vliet, O., Hanger-Kopp, S., Nikas, A., Spijker, E., Carlsen, H., Doukas, H., \& Lieu, J. (2020). The importance of stakeholders in scoping risk assessments-Lessons from low-carbon transitions. Environmental Innovation and Societal Transitions, 35, 400-413.

Verbong, G., \& Geels, F. (2007). The ongoing energy transition: Lessons from a socio-technical, multilevel analysis of the Dutch electricity system (1960-2004). Energy Policy, 35(2), 1025-1037.

Von Schomberg, R. (2013). A vision of responsible research and innovation. In Responsible innovation: Managing the responsible emergence of science and innovation in society (pp. 51-74). 
Winans, K., Kendall, A., \& Deng, H. (2017). The history and current applications of the circular economy concept. Renewable and Sustainable Energy Reviews, 68, 825-833. https://doi.org/10.1016/j. rser.2016.09.123

World Economic Forum, Ellen MacArthur Foundation and McKinsey \& Company. (2016). The New Plastics Economy-Rethinking the future of plastics. Retrieved March 22, 2020, from http://www. ellenmacarthurfoundation.org/publications.

Yurtsever, M. (2019). Glitters as a Source of Primary Microplastics: An Approach to Environmental Responsibility and Ethics. Journal of Agricultural and Environmental Ethics, 32, 459-478. https:// doi.org/10.1007/s10806-019-09785-0

Zwier, J., Blok, V., Lemmens, P., \& Geerts, R.-J. (2015). The ideal of a zero-waste humanity: Philosophical reflections on the Demand for a bio-based economy. Journal of Agricultural and Environmental Ethics, 28(2), 353-374.

Publisher's Note Springer Nature remains neutral with regard to jurisdictional claims in published maps and institutional affiliations. 